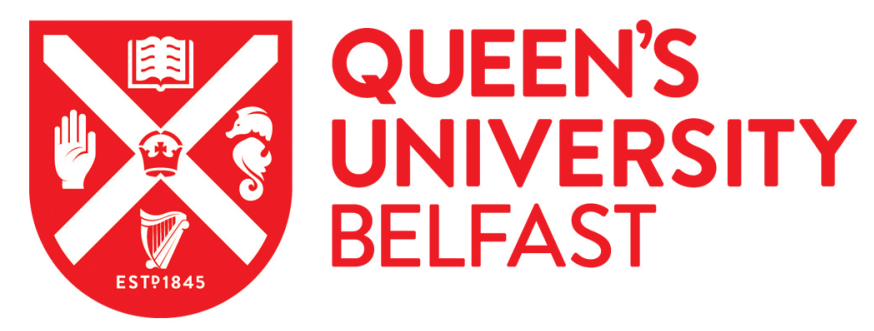

\title{
Poverty, inequality, child abuse and neglect: Changing the conversation across the UK in child protection?
}

Featherstone, B., Morris, K., Daniel, B., Bywaters, P., Brady, G., Bunting, L., Mason, W., \& Mirzah, N. (2017). Poverty, inequality, child abuse and neglect: Changing the conversation across the UK in child protection? Children and Youth Services Review. https://doi.org/10.1016/j.childyouth.2017.06.009

Published in:

Children and Youth Services Review

Document Version:

Peer reviewed version

Queen's University Belfast - Research Portal:

Link to publication record in Queen's University Belfast Research Portal

Publisher rights

Copyright 2017 Elsevier. This manuscript is distributed under a Creative Commons Attribution-NonCommercial-NoDerivs License

(https://creativecommons.org/licenses/by-nc-nd/4.0/), which permits distribution and reproduction for non-commercial purposes, provided the author and source are cited.

\section{General rights}

Copyright for the publications made accessible via the Queen's University Belfast Research Portal is retained by the author(s) and / or other copyright owners and it is a condition of accessing these publications that users recognise and abide by the legal requirements associated with these rights.

Take down policy

The Research Portal is Queen's institutional repository that provides access to Queen's research output. Every effort has been made to ensure that content in the Research Portal does not infringe any person's rights, or applicable UK laws. If you discover content in the Research Portal that you believe breaches copyright or violates any law, please contact openaccess@qub.ac.uk. 
Poverty, inequality, child abuse and neglect: Changing the conversation across the UK in child protection?

\section{Authors}

*Brid Featherstone ${ }^{a}$

Kate Morris ${ }^{b}$

Brigid Daniel ${ }^{\mathrm{c}}$

Paul Bywaters ${ }^{\mathrm{d}}$

Geraldine Bradye

Lisa Bunting ${ }^{f}$

Will Masong

Nughmana Mirzah

aProfessor of Social Work, School of Human and Health Sciences, University of Huddersfield, HD1 3DH UK: b.m.featherstone@hud.ac.uk

bProfessor of Social Work, Department of Sociological Studies, University of Sheffield,S10, 2TU, Sheffield, UK: kate.morris@sheffield.ac.uk

'Professor of Social Work, Faculty of Social Sciences, University of Stirling, FK9 4LA, UK: b.m.daniel@stir.ac.uk

dProfessor of Social Work, Faculty of Health and Life Sciences, Coventry University, CV1, 5FB, UK: paul.bywaters@coventry.ac.uk

eReader in Sociology of Childhood and Youth, Faculty ofHealth and Life Sciences, Coventry University, CV1 5FB, UK: g.brady@coventry.ac.uk

fLecturer in Life Course Research, School of Social Sciences, Education and Social Work, Queen's University, Belfast, UK: I.bunting@qub.ac.uk

gResearch Associate, Department of Sociological Studies, University of Sheffield, S10, 2TU, UK: w.j.mason@sheffield.ac.uk

${ }^{h}$ Research Fellow, Centre for Child-Wellbeing and Protection, University of Stirling, FK9 4LA, UK: nughmana.mirza@stir.ac.uk

*Corresponding author: b.m.featherstone@hud.ac.uk 
Poverty, inequality, child abuse and neglect: Changing the conversation across the UK in child protection?

\begin{abstract}
This article explores the evidence on the relationship between poverty, inequality and child abuse and neglect. It argues for the importance of developing further work on the implications of inequality, in particular, as this is a significantly underdeveloped area of study despite compelling evidence of its pertinence to the harms that children and their families experience. Drawing from the findings of a quantitative study that an 'inverse intervention law' appeared to be in operation with systematic unequal implications for children, the conceptual thinking behind a new qualitative study to explore why and how this law operates is explained. The implications for policy and practice are discussed in order to promote further debate about what is often a neglected or invisible aspect of child protection.
\end{abstract}

\title{
Keywords
}

Poverty, inequality, inverse, intervention, child protection 


\section{Introduction}

The relationship between poverty, child abuse and neglect is an area of child protection where there has historically been contention, debate and scholarship. However, in recent years in the UK, there has been less attention paid to understanding this relationship and to developing systematic research in this area, by contrast with a fairly substantial body of research in the USA (Bywaters et al., 2016). Indeed, in England, although with increasing divergence across the other UK countries, this debate is particularly evident with a strong political message that there is no relationship between poverty and the likelihood of a child being harmed or neglected. It is argued that it is irresponsible on the part of social work educators (and others) to suggest such a link (Gove, 2013). Furthermore, there has been little attention paid internationally to the relationship between child abuse and neglect and levels of inequality within society (see, however, Eckenrode et al., 2014). This is despite a growing, well-publicised and robust evidence base in the last decade on the relationship between inequalities and a host of social concerns such as addiction and mental health problems; problems that are highly pertinent to understanding and dealing with harms that children experience (Wilkinson and Pickett, 2009).

This discussion paper argues for the need for a re-engagement with poverty and inequality in order to understand the contribution to child abuse and neglect and in order to shape child protection responses informed by this understanding. The paper echoes the calls from many others internationally (see for example, Pelton, 2015) to interrogate and better understand how practices within child protection work in relation to children's different socio-economic circumstances.

The paper is informed by the findings from a study in England (the Coventry study) by Bywaters et al. (2014a; 2014b) about the links between living in an area of deprivation (as a marker of disadvantaged family socio-economic circumstances) and a child's chances of becoming the subject of formal state interventions. This confirmed the findings of multiple national and international studies that poor children are more likely to be the subject of child protection and care proceedings. However, the study, 
in drawing from the health inequalities literature, broke new ground, with findings which suggested that an 'inverse intervention law' (IIL) operated. This concept parallels the health 'inverse care law' which rules 'that the availability of good medical care tends to vary inversely with the need of the population served' (Tudor-Hart, 1971, p.411). Therefore, the poorest people in society who have a greater chance of poor health and the highest need for the best healthcare are less likely to receive it. Furthermore, there is a 'social gradient' which means every step up the socioeconomic ladder leads to an increase in health. The 'inverse intervention law' suggests that once deprivation is controlled for at the neighbourhood level, affluent Local Authorities (LAs) intervene (as defined by conducting child protection proceedings and removing children from home) more readily than less affluent LAs. Put simply, this means that children in similarly deprived circumstances face profoundly unequal chances of state intervention (no assessment is made here as to whether there is too little or too much intervention, this is not a study of outcomes). We will argue this finding suggests the need to engage not only with the issues arising from poverty but also from inequality and being poor in an unequal society.

The findings from the Coventry study prompted a successful application for further funding which has supported the large study that is currently underway. This is being conducted across the four countries of the UK. The study is:

a) Testing out the overall finding on the relationship between area level deprivation and a child's chances of being subject to particular state interventions

b) Through case-studies, using qualitative and quantitative measures, exploring the operation of the 'inverse intervention law'. This article describes this latter element of the study, and sets out the research questions.

However, given that poverty and inequality have been rendered either irrelevant or invisible in many contemporary discussions on child abuse and neglect, we firstly offer an overview of why we see this as both misguided and limiting in order to discuss the value and challenges of the study underway. 


\section{Poverty, child abuse and neglect}

Definitions of poverty are much debated. Some of the debates tend to revolve around whether to use measures of absolute or relative poverty and whether to focus on material resources or to include broader measures of what allows for acceptable living standards and social inclusion. In recent years, the government in England has proposed a radical departure from either approach, with its proposals to uncouple any link with income. This is out of line with the vast majority of organisations working in this field and other countries, most of whom incorporate approaches to income measurement which have a relational component. Currently, for example, the Child Poverty Action Group uses the definition advanced by one of its founders, Peter Townsend, in 1979:

Individuals, families and groups in the population can be said to be in poverty when they lack resources to obtain the type of diet, participate in the activities and have the living conditions and amenities which are customary, or at least widely encouraged and approved, in the societies in which they belong.

\section{(http://www.cpag.org.uk/content/what-is-poverty)}

A recent report for the Scottish Government on poverty and inequality stresses the importance of using relative poverty figures, and demonstrates the huge impact that housing costs can have in exacerbating poverty and inequality (Eisenstadt, 2016).

While shortage of material resources are at the heart of the hardships experienced by families, definitions also have to engage with rights and relationships, how people are treated and how they regard themselves. Shame has been described as the "irreducible absolutist core in the idea of poverty" (Sen, 1983, p.159). Shame forms an integral part of the "discursive "truths" that directly shape how poverty is perceived and responded to in policy and practice (Chase and Walker, 2015, p.256). The belief that poverty is shameful and a reflection of individual failings is a central feature of media and policy constructions of poverty (Gupta, et al., 2016). 
Consequently, as well as its material effects, people living in poverty must live with the shaming attitudes of others towards them, including the highly stigmatising tone of various public debates (Walker, 2014). In a study of the relationship between poverty and shame conducted across seven countries over a two-year period (201012), Walker et al. (2013) concluded that adults and children in all countries often felt ashamed because of the poverty they experienced.

The social and psychological pain of the shame reported by people living in poverty is important for its own sake, but also because shaming discourses are known to actively reduce self-confidence (Gupta et al., 2016). As Walker et al. argue from their study, "To survive on a low income in very challenging conditions requires considerable skill, inventiveness and fortitude", (2013, p.5); qualities that are made all the more necessary when people living in poverty are so readily dismissed as "feckless and lazy". For the British respondents in the study, subjective feelings of shame were especially strongly associated with parenting (see Gupta et al, 2016). The stigma associated with being subject to child protection proceedings in jurisdictions like those in the UK that have an adversarial ethos can further enhance feelings of shame.

There is a considerable literature on the social construction of child abuse and neglect which has highlighted how structural oppressions such as those emanating from classed, gendered and racialised inequalities get screened out in favour of a focus on individual causes rooted in individual deficits (see for example, Parton, 1985, 2014). This social construction of the 'problem' is inextricably bound up with a particular social construction of the activities involved in child protection. This, in turn, has serious implications in terms of rendering invisible the contribution poverty makes. Thus across many countries, there appears to be a settled view that abuse and neglect are activities that are individually understood and dealt with in a context where risk is omnipresent and attached to individuals' actions or inactions, choices or characters (Featherstone et al., 2016). There is a long history of explaining causes of abuse and neglect as lying in individual psyches or inter-personal dynamics (or more recently in England as being located in the choices individuals make). In all these scenarios poverty either has no role or is a background factor, never a leading player. 
The implications of constructing child protection in an individualist way in a context of risk are wide-ranging. These are felt most acutely by families who report feeling judged on home visits about issues that are beyond their control (no food in the fridge or no carpeting in children's bedrooms).

There's no regard for the fact that they could come to your house one day and you could have a very real reason for not being up to par or a bit frazzled, something's gone on or you haven't put the hoover round, it's packed up, if you can afford one. And then they just make it what they want to make of it, make it something else. And it's how they judge the contexts and make it about lists of negatives... (Parent quoted in Gupta et al., 2016, p.168).

Moreover, as a result of the focus on risk the investigation paradigm can become paramount as distinct from the helping one:

My family's first involvement with social services was brought about by me calling them, it took three attempts to get them to come in. Instead of coming in to help us they turned it around and tried to take the kids away. The need to judge has to change. Textbook cases are not what real life is all about. (Parent quoted in Gupta et al., 2016, p.164)

Poverty is living day to day and making ends meet. The money you have is not enough to provide for your kids. My daughter was bullied at school for her clothes and not having the right fashions; she stopped attending school and I was threatened with prison. I don't like borrowing from family and friends so I asked for help from social services. Then a social worker came around, checked my cupboards and made me feel I had done the wrong thing by asking for help. (Parent in Gupta et al., 2016; p.164)

Whether there was substance or not to the concerns about children's wellbeing and protection in these households the experience of the parents was that the impact of poverty was not acknowledged. If parents do not feel that the full range of issues 
affecting their lives are being assessed then the likelihood of developing an effective working relationship with professionals is reduced.

There has long been opposition to the focus on the individual family and advocacy of the need to offer supports to compensate for the harshness of trying to survive in poverty (see Holman, 1999; Jack and Gil, 2003, 2010). Currently, these are evident in the calls for either a public health approach (Daniel et al., 2011; Parton, 2014) or the development of a social model of child protection (Featherstone et al., 2016). These approaches are, however, marginal in contemporary policy and practice debates, with little evidence of the paradigm shift needed to support new analyses.

\section{Inequality, child abuse and neglect}

The issue of shame speaks centrally to a very topical aspect of debates about poverty; what are its causes? Are these rooted in the choices made by individuals? What roles do circumstances or constraints play? Binaries abound in this area with differing welfare settlements reflecting wider societal understandings of the balance of responsibilities between the individual, family, community and state. However, over the last thirty years, there has been a clear move across a range of differing welfare systems (situated within a project that has become known as neo-liberalism) towards locating causes and solutions with the individual:

Neoliberalism is in the first instance a theory of political economic practices that proposes that human well-being can best be advanced by liberating individual entrepreneurial freedoms and skills within an institutional framework characterized by strong private property rights, free markets, and free trade. The role of the state is to create and preserve an institutional framework appropriate to such practices. (Harvey, 2005, p.2)

In such a project, the state's role to provide welfare or protection from the market is repudiated and/or seen as a drag on free enterprise and as contributing to individuals becoming dependent and unwilling to engage with work. There is also a version that 
reconstructs the role of the state, as in the social investment approach, as a facilitator or enabler of people taking responsibility for their own welfare and for the risks that accrue across the life course (see, for example, Lister, 2006).

A common feature across diverse systems as a result of the neo-liberal turn has been a rise in inequalities in income between different groups within societies. For example, Harvey (2005) highlights the change in the share of national income going to top income earners in a range of countries between the late 1970s and 1999. Huge concentrations of wealth and power emerged in a diverse range of countries.

The work of epidemiologists Wilkinson and Pickett (2009) has mapped the impacts of the rise in inequality. They have collected internationally comparable data on health and a range of social problems: mental illness (including drug and alcohol addiction), life expectancy and infant mortality, obesity, children's educational performance, teenage births, homicides, imprisonment rates and social mobility. Their findings suggest that there is a very strong link between ill health, social problems and inequality. Differences in average income between whole populations or countries do not seem to matter once a certain level is reached, but differences within those populations or countries matter greatly. The amount of income inequality in a country is crucial. Wilkinson and Pickett (2009) note findings from the data that levels of trust between members of the public are lower in countries where income differences are larger. For example, people trust each other most in the Scandinavian countries and the Netherlands, and least in very unequal countries.

Wilkinson and Pickett (2009) argue that inequality within a society 'gets under the skin' of individuals leaving them feeling unvalued and inferior. They draw from the work of the sociologist Thomas Scheff (1988) on shame to argue: 'Shame and its opposite, pride, are rooted in the processes through which we internalize how we imagine others see us' (Wilkinson and Pickett, 2009, p.41). Greater inequality heightens anxieties because it increases the importance of social status, thus social position becomes a key feature of a person's identity in an unequal society. 
A key contribution from Wilkinson and Pickett is the relational aspect of their analysis. The ranking that goes on in contemporary unequal societies creates levels of toxicity that affect everyone not just those in poverty and this may be really vital when trying to understand some of the issues that emerge from the original study by Bywaters et al. (2014a) and which are now the subject of our further work (explored below). Moreover, if the analysis is correct and there is now extensive supporting evidence (see Rowlingson, 2011) then it is to be expected that social concerns such as mental health problems, addiction and levels of violence, all issues pertinent to the child protection arena, increase as income inequality increases. Although they do not address the implications for child abuse and neglect, Wilkinson and Pickett (2009) do note:

In Chapter 4 we described how the general quality of social relationships is lower in more unequal societies, and in Chapters 5 and 6 we showed how inequality is linked to poorer physical and mental health and more substance misuse. It's not a great leap then to think how life in a more hierarchical, mistrustful society might affect intimate, domestic, relationships and family life. Domestic conflict and violence, parental mental illness, poverty of time and resources will all combine to affect child development (p.111).

Eckenrode et al. (2014) carried out a study in the US showing a link between inequality in different counties and levels of maltreatment. However, this is quantitative work and does not offer any findings in relation to how the link operates. More generally, the work on inequalities has not been drawn on systematically in terms of its implications for understanding the harms children and their families suffer. This is of concern given as we have highlighted the evidence of high rates of parental mental health difficulties, substance misuse issues and domestic abuse in families where child maltreatment occurs. As Featherstone et al. (2014) note, a key insight from the work on the consequences of the growth in inequalities in societies concerns how distances between groups are intensified, including between social workers and their service users. Within the last decades, greater distances emerged between individuals, groups and communities; these were physical and psychological and affected 
everyone. Featherstone et al. argue that these processes of distancing contributed to a breakdown in feelings of solidarity and commonality in the face of vulnerability and adversity. This distancing has had pernicious effects on the relationship between child and family social workers and families.

In summary, the research on inequality obliges us to focus not just on poverty although there is complete agreement on its crucial importance for everyday survival. It also obliges us to look at issues such as the relationships between different groups in society in terms of trust and distance and at the differing types and rates of social problems faced by people.

\section{Deepening the conversation: the contribution of inequity?}

It is this discussion of the consequences of inequality and experiences of inequity that make the findings from the early study in England of an 'inverse intervention law' (IIL) particularly important. The study being described in this paper will focus on the IIL through its fieldwork in the case studies. Technical details of the earlier study, which the new study builds upon, have been reported elsewhere (Bywaters et al., 2014a and b). In brief, the aim was to examine patterns of child welfare interventions (CWI) defined as being made subject to a child protection plan or being received into out of home care - in relation to deprivation and to aspects of identity such as gender, disability, ethnicity and age. Analysis was based on the routinely reported data in 13 Local Authorities in the English West Midlands at 31.3.12. This represented around $10 \%$ of all children in England. The data included age, gender, ethnicity, disability, reason for being on a child protection plan and legal status for being in out of home care. The overall affluence or deprivation of each LA was also noted. However, there can be huge variations in affluence and deprivation within LAs, so more fine-grained analysis was undertaken. The level of deprivation of the neighbourhoods in which children subject to child protection plans were living and the neighbourhoods from where children were received into out of home care were ascertained from the Index of Multiple Deprivation for clusters of postcodes used in the Census that represent an average population of 1,500 . 
Neighbourhoods were sorted into their deprivation rank nationally, regardless of which LA they were in. This allowed for examination of patterns of intervention in relation to relative deprivation of each neighbourhood alone as well as in relation to the overall relative deprivation of the host LA. We illustrate some key findings by drawing on data for the most deprived third and most affluent third of LAs and in relation to four fictitious white children who could be boys or girls - Kim, Jo, Sam and Leslie. We focus in this case on white children as the patterns are different for Black, Asian and children of Mixed Race and are reported elsewhere (Bywaters et al., 2014b).

Any LA in the UK will contain both affluent and deprived neighbourhoods but there are different distributions so that LAs as a whole can also be placed on a spectrum of very deprived or very affluent. With the available data it was possible to confirm the fact that a child's chances of CWI, that is being subject to a child protection plan or removed to out of home care, are systematically associated with the level of deprivation of their neighbourhood. So, as we turn to our four imaginary children it is important to emphasise that poor children, whatever their wider conditions, are more likely to be the subject of formal state intervention.

This increased chance of CWI can be illustrated by a comparison at neighbourhood level of the chances of being subject to CWI of two hypothetical children, Kim and Jo, who live in different neighbourhoods in the same LA. Their LA is among the most deprived third of LAs in England. Within this LA Kim lives in one of the most deprived $20 \%$ of small neighbourhoods in England, meaning they are most likely to be enduring harsh social and economic conditions. Jo lives in one of the most affluent $20 \%$ (quintile) of neighbourhoods, and is significantly less likely to be coping with the social and economic conditions that Kim faces. In the data from Bywaters et al.'s study, Kim was 35 times more likely than Jo to become subject to a Child Protection Plan and eight times more likely to be looked after away from home.

If we turn to one of the most affluent third of LAs in England the same pattern occurred. If we compare our second set of hypothetical children, Sam and Leslie, we can see the pattern repeated. Sam, a hypothetical child living in an affluent LA in a 
deprived area (the neighbourhood is in the most deprived quarter of neighbourhoods in England) is 14 times more likely to become subject to a child protection plan and nine times more likely to be looked after away from home than Leslie who lived in a neighbourhood in the most affluent quintile in the same LA.

Referring back to our early discussion, the experiences of these four hypothetical children mean we must address both the systemic unequal rates of intervention, and the relationship between poverty, inequality and children's life chances. For all four children we can see the same pattern emerging, the chances of experiencing formal child welfare interventions map across to the levels of deprivation in their neighbourhoods.

As we have noted above, the finding that there is a relationship between family socioeconomic circumstances and child welfare is not new (Bebbington and Miles, 1989) and has recently been reinforced by the work of Pelton (2015). However, the quantitative evidence to support the general assumption has been underdeveloped in many countries in the last twenty-five years (Bywaters et al., 2016) and action to redress these inequalities has been lacking. Particular findings emerging from the study also require further consideration and exploration. When we compare the experiences of the children across the two LAs an interesting pattern emerges that is strikingly similar to the inverse care law described in the health inequalities literature. Within the broader picture of the mapping of deprivation and intervention rates a more nuanced analysis become necessary, because not all similarly poor children face the same possibilities of intervention.

Sam, who lives in one of the deprived neighbourhoods in the affluent $L A$, is nearly twice as likely to be the subject of a child protection plan or to be looked after away from home as Kim, who lives in an equally deprived neighbourhood in the deprived LA. Sam has a greater chance of intervention than Kim even though they both live in similarly deprived neighbourhoods. Less deprived LAs intervene at a greater rate in deprived areas than deprived local authorities. And this is a pattern that occurs across 
the spectrum, not just in this binary comparison of very deprived neighbourhoods. The same pattern of difference between affluent and deprived local authorities is seen for every level of neighbourhood deprivation or affluence. Overall a child's chances of a formal child welfare intervention is much greater at higher levels of deprivation, but for any given level of deprivation a child in a less deprived local authority is more likely to be the subject of a formal intervention. (The rates also display a social gradient, not a simple analysis of deprivation resulting in increased levels of intervention but an incremental reduction in intervention rates as the deprivation rate reduces).

In summary, for our imaginary children, the order of likelihood of formal state intervention because of care or protection needs is set out in descending order:

1. Sam in a deprived neighbourhood within a less deprived LA has the highest chance of intervention.

2. Kim in a similarly deprived neighbourhood in a deprived LA has the next highest chance of intervention.

3. Leslie in an affluent neighbourhood in less deprived LA has the next highest chance.

4. Jo in an affluent neighbourhood in a deprived LA has the lowest chance of intervention.

Table 1: Rates per 10,000 children in high and low deprivation neighbourhoods in high and low deprivation local authorities

\begin{tabular}{|l|l|l|r|r|}
\hline & Local Authority & Neighbourhood & CPP Rate & LAC Rate \\
\hline Sam & Affluent & High deprivation & 106.6 & 140.7 \\
\hline Kim & Deprived & High deprivation & 56.5 & 89.3 \\
\hline Leslie & Affluent & Low deprivation & 7.7 & 15 \\
\hline Jo & Deprived & Low deprivation & 1.6 & 11.2 \\
\hline
\end{tabular}

This evidence is, of course, not just about these individual hypothetical children but about a systematic, structured relationship which the study demonstrated. The average CPP and LAC intervention rates in the affluent third of LAs are roughly double those in the disadvantaged third of LAs across every quintile of neighbourhood 
deprivation. As indicated, our current study is exploring through case-studies what lies behind the patterns of intervention with Sam, Kim, Leslie and Jo. The case studies will explore multiple variables (including staffing, caseloads, expenditure, local practices and resource utilisation and service knowledge).

\section{Exploring the inverse intervention law}

In examining the inverse intervention law in child welfare we consider it necessary to research measurable supply and demand issues, as identified below, alongside the narratives held by professionals and families about deprivation and inequality in different contexts and conditions. The model below sets out the variables we are considering and provides a postulated framework for the IIL:

The influence of demand and supply on intervention chances

\section{DEMAND}

Families and Communities

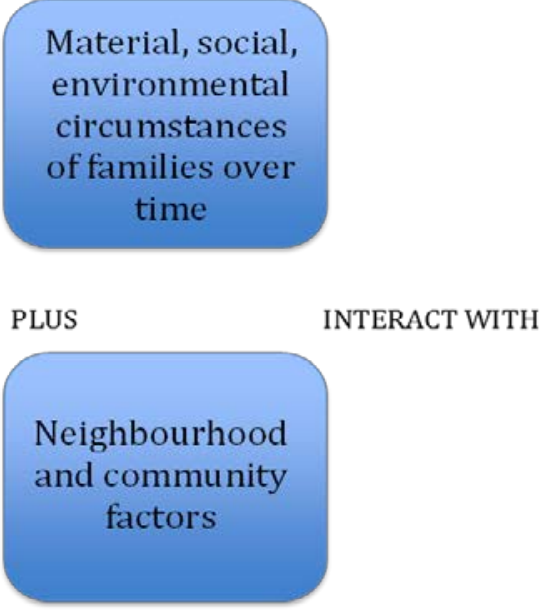

\section{SUPPLY}

The State/society
Intervention Chances
Law, policies, resources and practices
TO PRODUCE

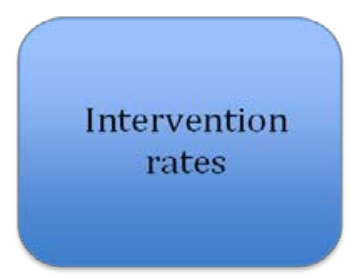

The case studies are exploring the complex interplay between the multiple variables that result in the unequal rates of intervention, and in particular the factors that create the inverse intervention law. More broadly they also allow the examination of the connection between intervention decisions and poverty and deprivation. The picture of inequality discussed earlier is compounded by the IIL, which suggests for 
children in similar socio economic circumstances different rates of intervention occur if they live in more or less deprived LAs. This raises multiple questions about equitable access for children and families to resources and help and LA decisions about the need for formal intervention (including staffing, access to family support, thresholds and risk management).

The established research reviewed in this article makes clear the impact of inequality on families, communities and services but we know very little about decisions to intervene in the context of significant inequalities. (It is worth reinforcing that our focus is the decision to intervene, the study cannot generate data concerned with outcomes, this is simply too great a task for this one study).

The case studies have developed a series of guiding questions in order to take forward our understanding of this relatively under developed area:

1. In the most deprived neighbourhoods what regard is given by professional responses to the material, social and economic circumstances of children and their families when decisions are made to intervene? This is the elementary output from the case studies, we are seeking to interrogate the interaction that occurs between professional responses to children's social, material and economic conditions and the decision making processes (including access to and use of resources). Families in the most deprived neighbourhoods have a particular experience of interventionist practice. Namely, they are the group most likely to be the subject of any formal state intervention. The studies will allow us to capture some insights into the interplay of the variables (access to resources, economic, social and material conditions, professional practices and policies) and to better understand what this means for protective and care decisions.

2. How do inequalities in the provision and access to resources influence decisions to intervene? Here we begin to touch upon the IIL as we start to explore, once we control 
for deprivation, why and how less deprived authorities intervene more readily in children's lives. Are greater resources resulting in the ability to respond to a greater number of children, children that have the same needs in other authorities but cannot be helped because of inadequate resources? Or are thresholds for intervention lower in authorities with greater resources? By controlling for deprivation in our choice of sites we will be able to build a comparative analysis that opens up some of these themes.

3. How does the experience of deprivation in deprived areas differ from experiences of similar levels of deprivation in less deprived areas? Here we arrive at some of the critical questions arising from adopting an inequalities lens. How do professionals' narratives about the impact of deprivation differ across sites? How do families' experiences and profiles differ across the case study sites? As the preceding discussion has made clear, a focus on levels of deprivation and their impact is not enough, the IIL demands that we ask different questions. For families in less deprived areas and authorities there are distinct differences in their experiences and the professional responses that might help us to understand the inequalities in intervention rates. The relational nature of the experiences of families and professionals is argued in the preceding discussions to be a critical factor in understanding how inequality impacts well-being, alongside notions of shame, suffering and the distance between professionals and families in an unequal society. Our study will begin to examine these complex themes and seek to arrive at insights into how these factors come together in the decision to intervene in a child's life.

In the latter stages of our fieldwork we will be coproducing with family members data that focuses on their experiences of living within areas of higher intervention. We will consider how loss and shame inform family responses, and the practices adopted by families to deal with these experiences. Working closely with family led organisations, data will be generated that allows us to contrast the professional and the family narratives, and to consider the implications for policy and practice. 
This is complex terrain both conceptually and methodologically and we can only anticipate starting to develop insights. There may well be more questions raised than answered but it is hoped that a refocusing of attention on deprivation and inequality can offer a significant contribution to developing professional practices and child welfare policies.

\section{Discussion}

One of the tensions in the study of child protection systems is that it is not possible to state what the 'correct' rate of child welfare intervention is or should be in the current context. Clearly a higher level aspiration is to eradicate the need for child protection services; but at the moment, crudely, the inverse intervention law could be used equally to argue for greater intervention in poorer local authorities or less intervention in more affluent authorities. Our study is not designed to provide evidence for either position, rather it is designed to examine the nature of engagement with underlying inequalities both in the demand of, and supply of, services and to render these inequalities more visible to inform policy and practice development.

We are also concerned to challenge and re-think a disconnect that has emerged between child protection policy and practice and wider social policies. Over the past thirty years, services which provided financial, housing and legal advice have been distanced from children's services practice and reduced. Alongside this the welfare system has become more complex and abrasive, and capacities in relation to housing have been severely curtailed by successive policy decisions favouring home ownership and private market provision. For families the focus on risk in individual cases and on shorter time scales for parents to demonstrate their capacity to change can have harsh implications. We have, as a result of political decisions about austerity, seen support services reduced, accompanied by early and decisive decision making with adoption a central priority (in England). Such developments have all shifted attention away from the material basis of family life, what in terms of Maslow's (1943) hierarchy of needs 
are the basis for human development: the food, water, warmth, rest, security and safety that a sufficient income and adequate, affordable housing in a safe environment represent.

However, it is important to note that child welfare policy is diverging across the UK and future outputs from our current study which is UK wide will provide more detailed comparative analyses. The devolved regimes in Scotland, Northern Ireland and Wales espouse more explicit policies aimed at providing early intervention and prevention with a greater emphasis on family support approaches than those currently expressed in England. In Scotland, in particular, there is political emphasis on the need to tackle inequalities for children and especially inequalities in educational outcomes. However, it is also important to note that families across the whole of the UK are affected by UK wide austerity measures and associated rises in inequality and practitioners working in statutory child protection settings are encountering families facing similar challenges.

The discussion in this paper and the work underway on the current study suggest a number of potential implications and considerations for policy and practice at all levels of the system. Policy that focuses primarily on the individual behaviours of parents and of practitioners may improve the protection of some individual children and may improve the experiences of some parents, but will not lead to serious inroads into the overall prevalence of harm to children. Thus it is vital that policies for children and families are joined up and policy makers are supported to see the connections between what are often quite siloed areas currently.

The work we have already undertaken reviewing the literature and the preliminary analysis of our data confirms the findings by Bywaters et al. (2014a; 2014b) that suggest that there could be merit in revisiting the way in which resources for children and families' services are allocated and distributed between and within local areas.

The case study work, outlined above, is examining expenditure data as part of the focus on supply and demand. While this is still at an early stage, we note indications 
of the need to pay careful attention to the relationship between levels of help, support and services and poverty and deprivation. Moreover, recent work by Hood et al. (2016) is of importance here as it supports the finding of an inverse intervention law and draws attention to the adverse consequences for deprived areas of current funding policies across the UK.

While government funding may (in some regions and countries) already take local socio-economic characteristics into account, the inverse intervention evidence suggests that the weighting of material disadvantage may be insufficient. The same arguments may apply at a more local level: is sufficient attention paid to the material conditions in different neighbourhoods in allocating resources and designing patterns of service? Our review of the literature strongly suggests that the significance of the socio-economic conditions for children's chances of experiencing risk or harm has to be reflected in the focus of services as well as the distribution of resources.

At the local level there are ways in which the learning about poverty and inequality could be incorporated more overtly into local children's services strategies. The concept of health inequalities and the inverse care law are now well-established and understood in the health profession. With the increased integration of health and social care and with the growing expectation that health professionals take an active role in the protection and safeguarding of children as part of a multi-disciplinary endeavour, there appears to be an ideal opportunity for cross-fertilisation of ideas. For example, multi-disciplinary local children safeguarding boards (LSCBs) in England could draw on the expertise of their colleagues in health and their insights from the field of health inequalities to inform their strategic planning.

At the level of practice, local procedures and guidance could be augmented with much more overt attention to issues of poverty and inequality, not as a backdrop to concerns about children, but as central and in the foreground. The rising use of practice models (such as Signs of Safety, systemic family practice) could be reviewed and expanded to foreground consideration of children's social material circumstances. Similarly, procedures for the supervision and management of cases 
could require that issues of poverty and inequality are engaged with actively in case planning.

Munro (2011) identified the limitations of seeking solutions to systemic problems in child protection responses by trying to regulate individual practitioners to work differently. Instead, she argues for a systems analysis. We anticipate that our case study research with practitioners can throw further light on practice challenges and professional attitudes and offer critical insights into how current practice can be supported to better respond to issues of poverty and inequality. We recognise the need for a multilayered response, and that changes to case work practice alone can have limited impact. We are also mindful that practitioners are only one part of a complex jigsaw and they also require changes elsewhere in the systems in order for their work to be supported and effective.

As this overview indicates, connecting with and utilising our knowledge of the relationship between poverty, inequality, abuse and child welfare interventions can open up fresh opportunities for new directions in policy and practice. In judging the appropriateness of rates of child protection and out-of-home care interventions within and between localities, the Bywaters et al. study demonstrates that it is essential to take into account the socio-economic conditions of the population at the neighbourhood level. The current study will raise important questions for data gathering and mining, and make recommendations for developments that can offer a nuanced understanding of interventions and care rates.

\section{Conclusion}

This article argues for an engagement with the evidence in relation to poverty and inequality in order to understand and change practices in child protection, indeed it raises the prospect of a paradigm shift in order to redress rather than reinforce child welfare inequalities. Drawing from the findings of a quantitative study that an inverse intervention law appeared to be in operation with systematic implications for children, the conceptual thinking behind a new qualitative study being developed to 
explore why and how this law operates is explained. Some implications for policy and practice are suggested in order to promote further debate about what is often a neglected or invisible aspect of child protection. In so doing we offer the opportunity to think afresh about how we both understand the experiences of children and families and the drivers of demand, and how we construct the supply of services in response.

\section{References}

Bebbington, A. and Miles, J. (1989) 'The background of children who enter local authority care', British Journal of Social Work, 19, 349-368.

Bywaters, P., Brady, G., Sparks, T. and Bos, E. (2014a) 'Child Welfare Inequalities: New Evidence, Further Questions', Child \& Family Social Work doi.wiley.com/10.1111/cfs.12154

Bywaters, P., Brady, G., Sparks, T. and Bos, E. (2014b) 'Inequalities in Child Welfare Intervention Rates: The Intersection of Deprivation and Identity', Child \& Family Social Work doi.wiley.com/10.1111/cfs.12161

Bywaters, P., Brady, G., Sparks, T., Bos, E., Bunting, L., Daniel, B., Featherstone, B., Morris, K. and Scourfield, J. (2015) 'Exploring inequities in child welfare and child protection services: explaining the "inverse intervention law", Children and Youth Services Review, v. 57, October, pp. 98-105 doi.10.1016/j.childyouth.2015.07.017

Bywaters, P., Bunting, L., Davidson, G., Hanratty, J., Mason, W., McCartan, C. and Steils, N. (2016) The relationship between poverty, child abuse and neglect: an evidence review. York: Joseph Rowntree Foundation.

Chase, E. and Walker, R. (2015) Constructing reality? 'The discursive truth of poverty in Britain and how it frames the experience of shame'. In Poverty and shame: global experiences, Chase, E. and Bantebya-Kyomuhendo, G. (eds) Oxford: OUP, 256-269.

Daniel, B. Taylor, J. and Scott, J. with Derbyshire, D. and Neilson, D. (2011) Recognizing and Helping the Neglected Child: Evidence-Based Practice. London: Jessica Kingsley Publishers.

Eckenrode, J., Smith, E., McCarthy, M. and Dineen, M. (2014) 'Income inequality and child maltreatment in the United States, Pediatrics. doi: 10.1542/peds.2013-1707

Eisenstadt, N. (2016) Independent Advisor on Poverty and Inequality: Shifting the curve - a report for the First Minister, Edinburgh, 
Featherstone, B., Gupta, A., Morris, K. and Warner, J. (2016) 'Let's stop feeding the risk monster: towards a social model of "child protection", Families, Relationships and Societies http://dx.doi.org/10.1332/204674316X14552878034622

Featherstone, B., White, S. and Morris, K (2014) Re-Imagining Child Protection: Towards Humane Social Work with Families. Bristol: The Policy Press.

Gove, M. (2013) Getting it right for children in need. Michael Gove speech to the NSPCC, https://www.gov.uk/government/speeches/getting-it-right for-children-inneed-speech-to-the-nspcc

Gupta, A., Burhardt, H. and ATD4th World (2016) 'In the Lion's Den: families' experiences of social work practice in a risk-averse child protection system', Families, Relationships and Societies, 5 (1): 153-172.

Harvey, D. (2005) A short history of neoliberalism. Oxford: Oxford University Press.

Holman, B. (1999) Faith in the Poor. Oxford: Lion Hudson.

Jack, G. and Gill, O. (2003) The Missing Side of the Triangle: Assessing the Importance of Family and Environmental Factors in the Lives of Children. Barkingside: Barnardo's.

Jack, G. and Gill, O. (2010) 'The role of communities in safeguarding children and young people', Child Abuse Review 19(2): 82-96.

Jack, G. and Gill, O. (2013) 'Developing cultural competence for social work with families living in poverty', European Journal of Social Work, 16(2) pp. 220-234. ISSN 1369-1457.

Lister, R. (2006) 'An agenda for children: investing in the future or promoting wellbeing in the present?' In Lewis, J. (ed.) Children, changing families and welfare states. Cheltenham: Edward Elgar.

Maslow, A. H. (1943) 'A Theory of Human Motivation', Psychological Review, 50(4): 370-96.

Munro, E. (2011) The Munro Review of child Protection: Final report- $A$ child centred system. London: Department for Education.

Parton, N. (1985) The Politics of Child Abuse. London: Macmillan. 
Parton. N. (2014) The politics of child protection. Basingstoke: Palgrave.

Pelton, L. (2015) 'The continuing role of material factors in child maltreatment and placement', Child Abuse \& Neglect 41: 30-39.

Rowlingson, K. (2011) Does Income Inequality Cause Health and Social Problems? York: Joseph Rowntree Foundation.

Sen, A. (1983) 'Poor, relatively speaking', Oxford Economic Papers, 35: 153-69.

Tudor-Hart, J. (1971) 'The inverse care law', The Lancet, 297, 7696, 405-412.

Townsend, P. (1979) Poverty in the United Kingdom. Harmondsworth: Penguin Books.

Walker, R. (2014) The shame of poverty. Oxford: OUP.

Walker, R., Bantebya Kyomuhendo, G., Golooba-Mutebi, F., Lødemel, I., Pellissery, S., Ming, Y. (2013) Shame, Social Exclusion and the Effectiveness of Anti-Poverty Programmes: A Study in Seven Countries ESRC End of Award Report, RES-167-25-0557. Swindon: ESRC.

Wilkinson, R. and Pickett, K. (2009) The Spirit Level: Why More Equal Societies always do better. London: Penguin. 